\title{
Artworks from Valeriya N-Georg: exploring the body and soul
}

\author{
Valeriya N-Georg \\ Artist, London, UK \\ Correspondence to: Valeriya N-Georg. Artist, London, UK. Email: valeriyangeorg@gmail.com.
}

Submitted Jan 28, 2021. Accepted for publication Feb 07, 2021.

doi: $10.21037 / \mathrm{cdt}-21-79$

View this article at: http://dx.doi.org/10.21037/cdt-21-79

Recently, Cardiovascular Diagnosis and Therapy (CDT) is honored to have the opportunity to interview artist Valeriya N-Georg (Figure 1).

\section{Questions:}

1. How did art and science first get mixed together in your work? What role did neuroscience play?

2. Can you discuss the influence Antonio Damasio's research had on how you approach your work?

3. What are you exploring in your work?

4. While numerous aspects of the neuroskeletal system appear in your work, neurons feature prominently. What is their significance?

5. You rely on a wide range of media. How does the medium influence what you create? How does it further the themes you are exploring?

6. Can you discuss "Life and Death" and "Decay"? How do they fit in with your body of work?

7. Let's talk process for a moment. How do you go from the conception of "Corpus Fabrica" to its creation?

8. Who are your biggest influences?

9. Finally, what do you believe is the role of the Artist in society, if any?

\section{Valeriya's Answers:}

\section{How did art and science first get mixed together in your work? What role did neuroscience play?}

The intertwining of art and science started becoming a prominent theme in my work around 2011, a time when I was taking in a deep interest in psychology. Reading Freud's and Jung's discoveries about the subconscious and the human psyche, the importance of dreams, the switch between conscious and subconscious states, the purpose of death and

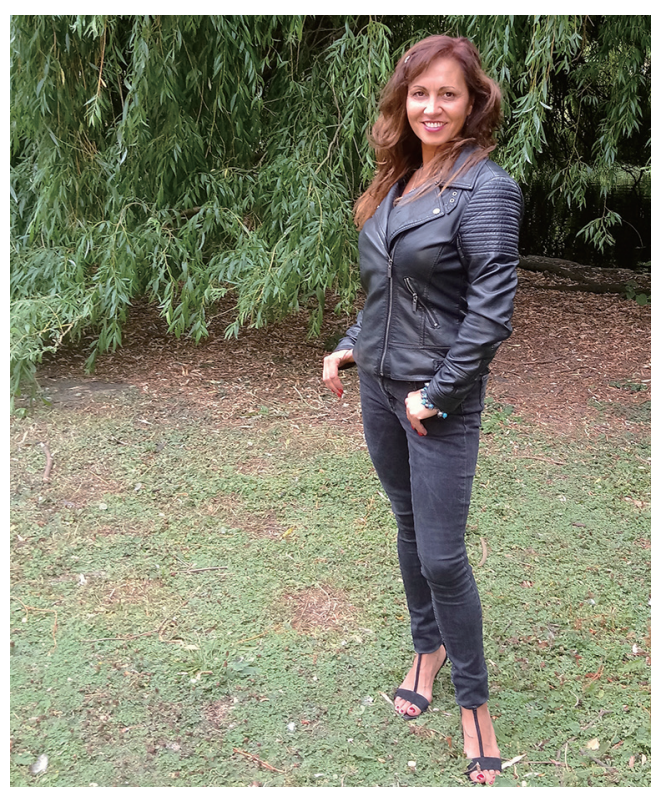

Figure 1 Valeriya N-Georg - Photo by Mona K. Art.

birth, led me to dedicate my artwork to establishing a link between the human heart (Figure 2,3) and brain (Figure 4), two major pillars of the human being and physical embodiments of the soul. I am interested in both Cardiology and Neurology, but somehow my focus has always been inclined more towards Neuroscience and its ability to explain the origins of human consciousness. The questions that kept popping up in my head were: Who we are? What we are, a body with a soul or a soul with a body? Why we are here? Why we do sleep? Why do we dream? Where do we go every night when we go to sleep? How does life come to be? How does consciousness arise? How are our bodies controlled unconsciously most of the time? Is that because the brain controls the body or it is because the spirit is living inside the body? Does the existence of consciousness simply 


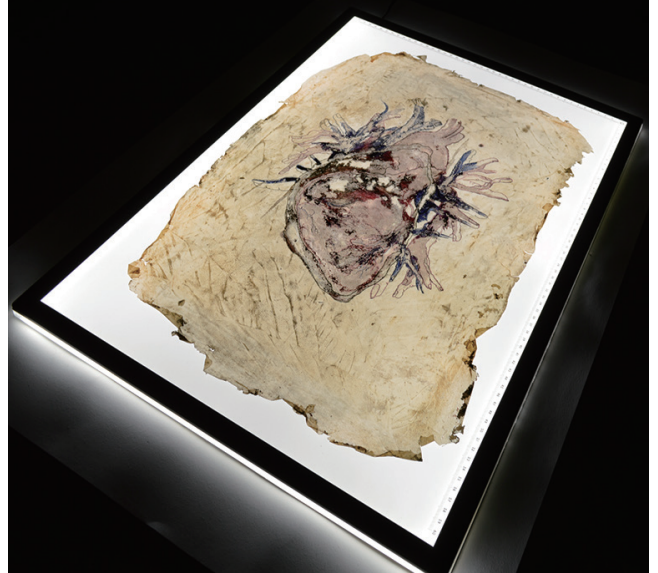

Figure 2 'Feel My Way'-1.

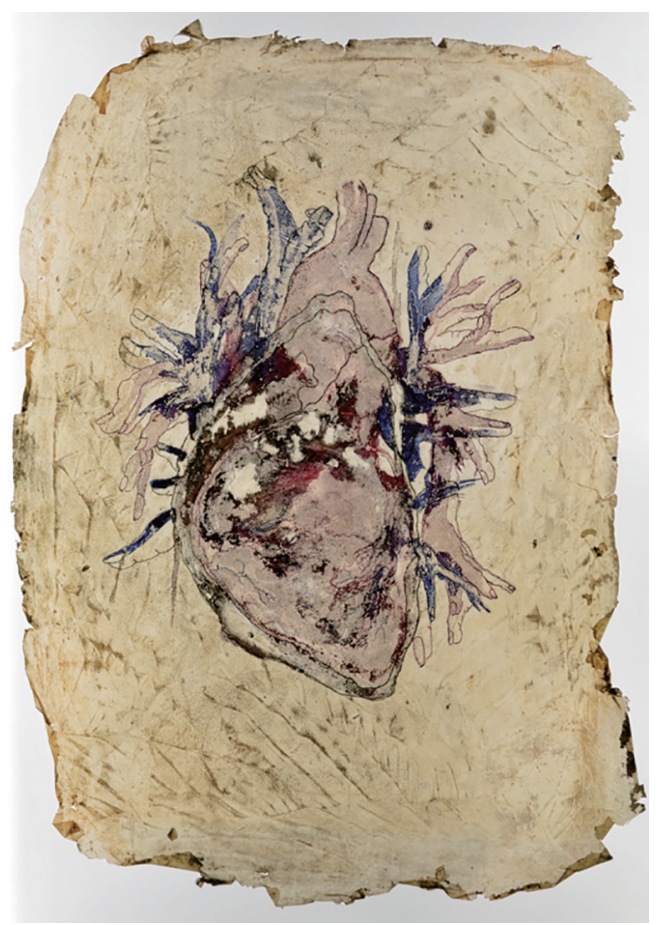

Figure 3 'Feel My Way'-2.

come down to the constant firing of neurons? Scientists have been tantalized by many years of neuroscience research as this greatest mystery of life remains unresolved.

\section{Can you discuss the influence Antonio Damasio's research had on bow you approach your work?}

My work has been deeply influenced by Antonio Damasio's

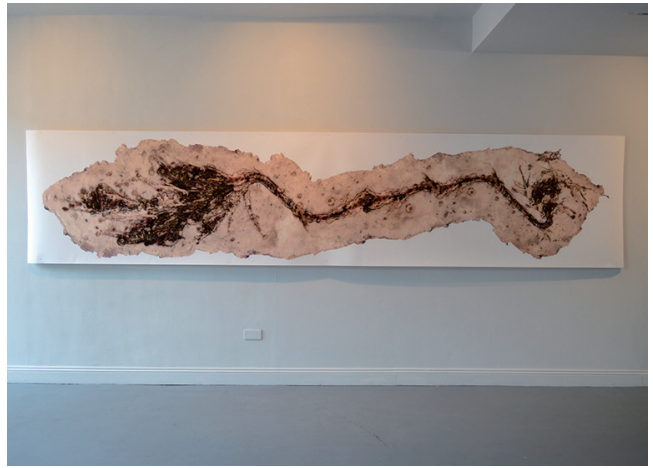

Figure 4 'Axon'.

research on the relationship between the brain and the consciousness, the role of emotions and feelings in defining life-regulating processes and the mental representations of our bodily states.

The way I approached my work fundamentally changed after reading Antonio Damasio's books 'Self Comes to Mind' and 'The Feeling of What Happens'. When I understood how the feelings of emotion can influence the body state, and not just how chemical messages are conveyed via the bloodstream and electrochemical signals are elicited via nerve pathways, but also via the alternative mechanism involving the 'as if body loop' where the changes created directly in the sensory body map (especially in the human skin, where there is the human sense of touch) give us the experience of emotion and feeling. Having emotions is essential to our survival. Emotions provide us with survival-oriented behaviors, which impact us deeply on an internal level. The overall experience of feeling when there is a shift in consciousness changes the chemistry in the body through the neural system following significant activity in the brain. My work 'Placebo' (Figures 5,6) is the first example that comes to mind, right now. This is my perception of the internal picture of the human body, and the piece not only depicts it conceptually but also conveys my physical approach to creating the art as part of the subject of matter. The effect over the viewer is one of my main objectives. This is quite important to me as I aim my art to have a specific energy healing effect, and to be able to provoke a positive change in the world in terms of wellbeing.

The main message from my artwork 'Placebo' is about the importance of positive thinking. What we think is what we create in our lives and this automatically changes the chemistry in our physical body and has the ability to heal illnesses that are considered incurable. 


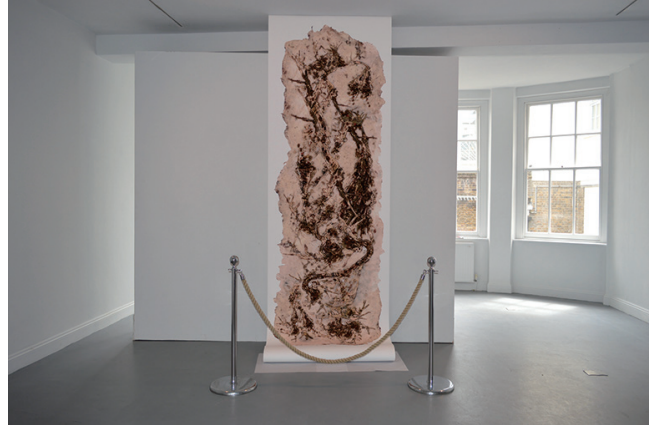

Figure 5 'Placebo'.

\section{What are you exploring in your work?}

It has been the focus of my work to unravel the relationship between the physical human body and the inner self (or the human spirit). In my practice I investigate the representation of the invisible by depicting fragments of the physical anatomy. I am interested in exploring the boundaries between the inner and outer body; between the physical and metaphysical; tangible and intangible, by exploring the tactile and the optical image.

My artworks present drawings of fingers referencing the sense of human touch, which is of utmost importance to the way we experience life on Earth. I am fascinated by the vastly complex network of nerve endings and touch receptors in the skin that define the way we perceive the material dimension of this world. The brain gets an enormous amount of information about the texture of objects through our fingertips, as their ridges are full of sensitive mechanoreceptors, which are our means of communication with the external world.

\section{While numerous aspects of the neuroskeletal system appear in your work, neurons feature prominently. What is their significance?}

Neurons are very important cells for the human body. The ability to perceive the surroundings with the human senses to see, hear, smell and touch depends on your nervous system. Also, the ability to recognize where you are and where you've been before, the memories you are keeping and the ability to act on information that indicates danger. Everything in the human body is controlled by the nervous system, sending signals to the brain and then the brain sending signals to the blood flow to your muscles and so on. To me the neurons are very significant part of the human body that enables the relationship with the human spirit.

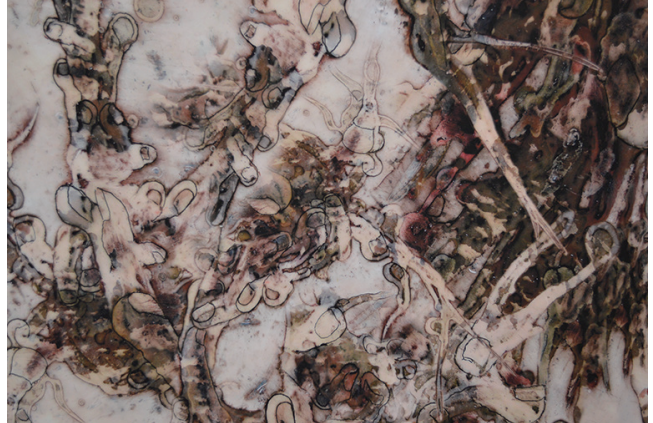

Figure 6 'Placebo'- Detail.

Consciousness arises when there is electrical activity between the neurons, everything depends on a group of neurons that work together and the communication between them is crucial. That's why I have decided to create my 5 meters work 'Axon'. I wanted to enlarge a single axon to a scale so that the viewer can immerse himself as a Alice in Wonderland and be able to witness the detail of interconnectedness of our own neuronal networks, to perceive it as a the transcendental, miraculous experience. What is there to learn? Imagine the people as neurons. To understand that single human being cannot exist alone, as we are humans are interdependent. The 'axons' between people are energies. They are not visible, but everyone is able to feel and sense the energies of the other. The Vibe! Vagus nerve is the latest work I am working on. But this is another big topic that deserves a separate discussion. To return to the question, the electrical impulses between the neurons could be seen as an exchange of words or physical movement between humans. Can you imagine a world where there is a perfect synchrony in the network? When the brain is lacking good orchestration of electrical impulse exchange between neurons, people are often being diagnosed with depression or a mental illness of a certain kind. So... what happens in our contemporary world? How do people communicate with each other? Why there are wars in different parts of the planet? How do people interact with the others to create wars? I hope that you and your audience understand what I am speaking about. There is a lot to be learned from the inside world of the human body.

\section{You rely on a wide range of media. How does the medium influence what you create? How does it further the themes you are exploring?}

Yes, I work with wide range of media, it largely depends on the project I am working on. Sometimes I use light, 


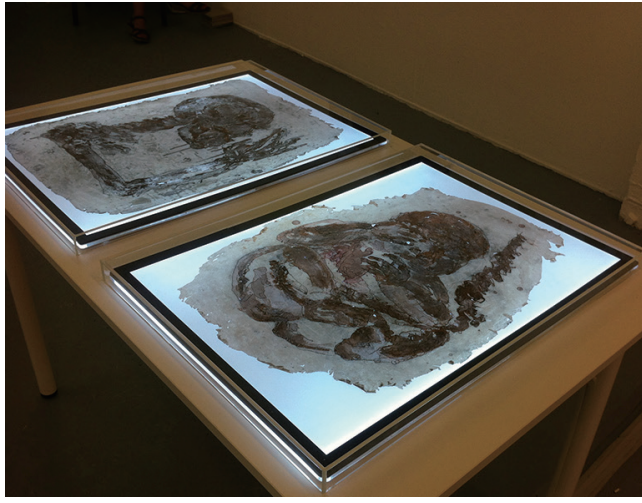

Figure 7 'Life and Death' - light boxes installation.

sometimes I use paper, sometimes the creation becomes 3D, all of this depends on what I am trying to communicate with my art in the type of gallery space it's being exhibited in. The light for example illuminates the ink print made upon the gel surface and conveys a sense of a medical forensic examination on the surgeon's table.

The materials I work with are different from the traditional ones used in printmaking. In my experimental days, I was trying to conceive a gel-like texture that visually resembles skin and brain tissue. The idea of using gel as my main art media was born by imagining the jelly-like fluid substance of the cytosol which makes up a significant part of all living cells.

Just as cells can make copies of themselves, I use digital printing to create large-scale digital collages made of numerous copies of smaller gel monotype prints. Constructing an image via layering allows me to explore the interplay between printmaking processes, handmade drawings and computer-generated images.

\section{Can you discuss "Life and Death" and "Decay"? How do they fit in with your body of work?}

'Life and Death' (Figure 7) and 'Decay' (Figure 8) are works displayed on LED boxes. As subject and concept Life and Death are inseparable from my other subject of work. In order for us to be alive, we need a body with a brain and heart, but I believe in order for consciousness to exist, before anything else, there needs to be a Soul or Spirit, inhabiting this body. 'Life and Death' are images of a baby in the womb epitomizing the beginning of life and a skeleton of a dead human where the spirit has already departed the body. My aim was to instil in the viewer a

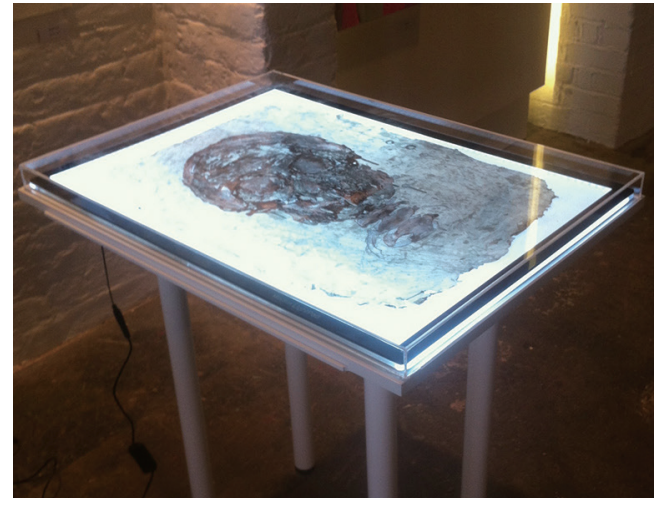

Figure 8 'Decay' - Light box installation.

feeling of contrast. 'Decay' is also about death. There are no more remnants of skin and flesh after the consciousness and the spirit have left the body in the physical form. These works were created a bit earlier in my artistic career. As you probably know most of the artists have different periods that have influenced their art. My artwork from 10 years ago was much more figurative and was inspired more by Psychology than Neuroscience and Consciousness. All these fields of study, however, are focussed on the human brain. All our thought and feelings are valid, as are our brain states. It all comes down to how the human brain actually functions and this is what scientists have been striving to understand for a long time now. As of recent my work has been more abstract.

\section{Let's talk process for a moment. How do you go from the conception of "Corpus Fabrica" to its creation?}

My solo show 'Corporis Fabrica' was held at Lubomirov/ Angus-Hughes Gallery in Hackney London, with the special assistance of the Curator Iavor Lubomirov, who came up with the title "Corporis Fabrica" after having a look at my work and noted that it reminded him of the anatomical book of Andreas Vesalius „De bumani corporis fabrica". The book was published in $16^{\text {th }}$ century and was based on Vesalius lectures, during which Andreas Vesalius deviated from common practice by dissecting corpses to illustrate what he was discussing. In the book he presents a careful examination of the organs and the complete structure of the human body, with copies of the book being bound in the skin of executed convicts.

Creating the work my intention was to make the viewer feel like he is inside the human body and brain, to try to 
provoke the viewer's imagination he to be able to feel like he is under the human skin. As Lubomirov so aptly put it:

"Valeriya N-Georg's Corporis Fabrica is an immersive print-based installation, in which scale and image combine to submerge viewers into a sense of their own physical self, a view from within, an experience of being both smaller and larger than themselves, of looking out from under their skin.

The work is a quest for the self within the anatomical body, for the notional mind which inhabits the body's neural network, but is perhaps somehow other than its physical substance. It takes on birth and death, the brain and the skin, the mind and the ways thought controls life by changing the chemistry in the body. For N-Georg Science and Art are inseparable. Neurology, Psychology, Consciousness studies and Philosophy all come into play on the surfaces which she uses, which act like dissecting tables on which she explores and recreates her sense of the substances of self."

\section{Who are your biggest influences?}

In terms of science, my work has been influenced by Antonio Damasio's as we already spoke about. Also, Dr. Bruce Lipton's ideas about the interactions between the mind and the body and the processes by which cells receive information. Leonardo Da Vinci's amazing drawings and scientific investigations have been a long-term inspiration for me.

In terms of contemporary art, James Turrell's luminous and immersive installations which engage the viewer to meditate and gain a new understanding of the materiality of light, colour and space, where we become aware of our own senses. And Bill Viola's use of innovative technology, video, sound and water exploring the phenomena of sense perception as a new means of self-discovery, as well as, his focus on universal human experiences such as birth, death, dreams and the unfolding of human consciousness.

\section{Finally, what do you believe is the role of the Artist in society, if any?}

The Artist has got huge role in the society. An artist can lead and uplift or provoke with their art. Depends on the personality of the artist, his/her work can evoke emotion that could change the world and the perception of it for the viewer. Contemporary artists nowadays are different than the artists that lived a while back. The art is no more as much about entertainment, decoration or illustration the way it used to be. Artists today think outside of the framework that society has created and their work encourages a much-needed dialogue within society. They are mostly free and honest individuals whose artwork is a statement of their own authentic truth seen through the lens of a ground-breaking and often underrepresented perspective. Today's society calls for artists to bring about change more than ever before.

\section{Acknowledgments}

Funding: None.

\section{Footnote}

Provenance and Peer Review: This article was commissioned by the editorial office, Cardiovascular Diagnosis and Therapy. The article did not undergo external peer review.

Conflicts of Interest: The author has completed the ICMJE uniform disclosure form (available at http://dx.doi. org/10.21037/cdt-21-79). VNG serves as an unpaid associate and guest editor of Cardiovascular Diagnosis and Therapy from Jul 2019 to Jun 2021.

Ethical Statement: The author is accountable for all aspects of the work in ensuring that questions related to the accuracy or integrity of any part of the work are appropriately investigated and resolved.

Open Access Statement: This is an Open Access article distributed in accordance with the Creative Commons Attribution-NonCommercial-NoDerivs 4.0 International License (CC BY-NC-ND 4.0), which permits the noncommercial replication and distribution of the article with the strict proviso that no changes or edits are made and the original work is properly cited (including links to both the formal publication through the relevant DOI and the license). See: https://creativecommons.org/licenses/by-nc-nd/4.0/.
Cite this article as: N-Georg V. Artworks from Valeriya N-Georg: exploring the body and soul. Cardiovasc Diagn Ther 2021;11(4):1200-1204. doi: 10.21037/cdt-21-79 